\title{
\#9
}

\section{Meretas Lanskap Idealisme Jurnalis dan Inovasi Bisnis Industri Media}

Hendra Alfani \& Masayu Indriaty Susanto

Bisnis industri media dan profesi jurnalis atau wartawan, memasuki tahapan krusial. Masif-nya perkembangan teknologi informasi dan komunikasi yang berbasis internet, telah melahirkan "budaya" baru dalam tata kelola bisnis industri media dan perubahan habit dalam profesi kewartawanan.

Sifat media massa yang serba hadir saat ini, keberadaannya tidak dapat dipisahkan dari kehidupan manusia. Perkembangan teknologi, terutama transportasi dan teknologi media, telah mengubah wajah dunia, batas-batas jarak dan waktu yang menjadi kendala masa lalu, kini telah teratasi (Samatan, 2009).

Kondisi ini memunculkan pertanyaan besar. Apakah konvergensi media menjadi satu-satunya solusi? Agar media konvensional (mainstream) dapat berdamai dengan situasi itu, dan secara perlahan mulai beralih menjadi media yang berbasis digital? 
Tentu tidak mudah menjawab dua pertanyaan fundamental ini. Apalagi ketika dua konteks mendasar dalam pertanyaan itu, dihubungkan dengan upaya bagaimana meretas langkah inovatif dalam bisnis industri media dan menghubungkannya dengan idealisme jurnalis dalam menjalankan profesinya.

Pada kenyataannya, era digitalisasi sekarang ini, bukan hanya memaksa bisnis media massa untuk segera "berganti kulit" tetapi juga telah mengondisikan setiap individu untuk terbiasa menggunakan berbagai aplikasi digital dalam menunjang aktivitasnya. Kondisi ini, suka ataupun tak suka, juga memengaruhi habit setiap individu dalam mengakses berbagai informasi, khususnya produk informasi yang diproduksi oleh media massa.

Mencermati kondisi itu, Paul Gillin, konsultan teknologi informasi dari Massachusetts, seperti dikutip Rahmad (2013), menyatakan bahwa model bisnis media cetak tidak mungkin lagi bertahan hidup. Perkembangan ekonomi sedang bergerak melawan bisnis cetak. Media cetak melibatkan banyak karyawan, sehingga biaya produksi lebih mahal dari media online. Apalagi, zaman sekarang, generasi muda lebih suka bermain internet daripada membeli majalah atau koran (Kusuma, 2016).

Kebiasaan yang beralih itu, dari konvensional ke digital, seiring perjalanan waktu mulai menggerus eksistensi media yang sudah begitu "nyaman" dalam waktu yang sangat panjang. Satu persatu media konvensional, khususnya media cetak berguguran tak mampu bertahan. Tiras terjun bebas dan omset iklan sebagai sumber pemasukan utama yang menghidupi media konvensional juga mulai beralih ke ruang digital.

Pun demikian halnya dengan konteks persoalan idealisme jurnalis. Idealisme bagi para jurnalis, pada era sekarang ini seolah menjadi serat adi luhung yang berada di menara gading. Sebuah keniscayaan yang harus selalu ada, luhur serta mesti dijaga dan 
diperjuangkan. Tetapi, sering kali idealisme para jurnalis, menjadi tak bertaji bahkan tak berdaya ketika dihadapkan dengan tembok tebal industri media di era kapitalisasi ataupun konsentrasi kepemilikan (konglomerasi) media yang makin menggurita dan memasung kebebasan serta kontrol media yang bermula dari idealisme para jurnalis dengan konsep adi luhungnya.

Fenomena konsentrasi media yang terjadi di Indonesia merupakan suatu kejadian yang benar-benar sedang terjadi dan menjadi perhatian oleh setiap orang. Pengaruh pada kompleksnya industri media massa mengakibatkan adanya konsentrasi kepemilikan menjadi suatu proses yang tidak dapat dihindarkan oleh setiap pelaku industri media massa (Razali, 2019).

Tulisan singkat ini, hendak berupaya berbagi perspektif pemikiran dalam meretas jalan pertemuan antara idealisme jurnalis dan inovasi bisnis industri media. Guna memastikan harapan dan keyakinan, bahwa pers atau media yang idealis itu tidak pernah mati dengan berbagai prasyarat yang selalu harus diperjuangkannya. Dus, demikian halnya dengan idealisme para jurnalis harus tetap tumbuh dan terjaga, walaupun berbagai ancaman dan tekanan senantiasa mengintainya.

\section{Pers Idealis Tidak Akan Mati, Tapi ...}

Pers adalah penjaga gerbang kebenaran, moralitas, dan suara hati dunia. Pers juga memegang fungsi kontrol sosial dan menjadi pilar keempat demokrasi. Ketika kebebasan pers diancam, diberangus, atau dilarang sama sekali, maka setiap kebebasan lainnya juga akan dibatasi. Dan demokrasi sendiri akan terancam.

Edmund Burke seperti digambarkan McQuaill (2011:185-187), menyebut media massa sebagai pilar keempat (fourth estate) demokrasi. Bahkan secara ekstrem, Burke, menyebut media memiliki kedudukan yang sejajar dengan Tuhan (Lord), Gereja 
(Church), maupun Majelis Rendah (Commons). Pendapat tersebut didasarkan pada kekuatan yang dimiliki oleh media massa dalam hal menyampaikan informasi sehingga media dapat meningkatkan publisitas atau bahkan justru menahannya. Media massa mampu melakukan kontrol terhadap pemerintah dan majelis atas dasar prinsip kebebasan untuk menghasilkan informasi yang dapat menjamin pelaksanaan demokrasi dan memajukan masyarakat. Oleh karena itulah, kebebasan pers merupakan hal yang esensial untuk menjamin eksistensi media sebagai pilar keempat demokrasi. Hakikat dari kebebasan pers pada dasarnya ialah keleluasaan bagi individu untuk menyampaikan pendapat tanpa adanya sensor, serta kemampuan media untuk melakukan kontrol terhadap pemerintah maupun kekuatan lain (Darmanto, 2015).

Artinya, jika mencermati pendapat Burke itu (seperti dikutip Darmanto, 2015), pers tidak boleh dibungkam, kontrol pers sebagai hakikat kebebasan pers harus diakui dan dihormati oleh siapa saja. Akan tetapi zaman (mungkin) berubah, oleh karenanya kebebasan pers yang dibungkam adalah isu global yang menjadi perhatian dunia saat ini. Pers yang seharusnya independen, justru dijadikan alat untuk meraih atau mempertahankan kekuasaan. Pers juga ditarik sebagai alat untuk mencapai berbagai kepentingan, baik kepentingan politik, ekonomi, bahkan juga personal.

Padahal, bagaimana kondisi kebebasan pers di suatu negara adalah salah satu barometer kualitas demokrasi di negara tersebut. Secara konseptual, kebebasan pers akan memunculkan pemerintahan yang cerdas, bijaksana, dan bersih. Karena hanya dengan pers yang bebaslah, komunikasi yang berkualitas antara rakyat dan pemerintah sebagai lembaga eksekutif yang menjalankan amanat dari rakyat, akan terjalin.

Rakyat akan mengetahui kinerja pemerintah dan melakukan kontrol yang intensif, komprehensif dan terukur. Dan pemerintah juga akan mengetahui bagaimana dampak kebijakan-kebijakan yang diambil 
terhadap masyarakat secara riil, dan dijadikan bahan evaluasi. Ini juga berlaku untuk parlemen sebagai lembaga legislatif dan lembaga-lembaga hukum negara sebagai unsur yudikatif.

Parlemen wajib mengetahui fenomena yang terjadi di masyarakat, sebagai bahan untuk memutuskan undang-undang apa yang diperlukan untuk menjamin ketertiban negara. Demikian juga, melalui pers, parlemen pun akan bisa mengetahui secara cepat dan akurat, bagaimana efek dari undang-undang yang mereka rancang dan sahkan. Termasuk bagaimana sebuah aturan dilaksanakan dan dipatuhi baik oleh pemerintah sebagai penyelenggara negara maupun masyarakat umum.

Banyak sekali aturan-aturan yang ternyata kemudian memicu polemik di masyarakat. Misalnya yang terkini, Undang-Undang Cipta Karya yang banyak memicu penolakan dari rakyat. Sebelumnya, ada lima rancangan undang-undang yang mendapat penolakan luas dari mahasiswa dan masyarakat. Yaitu Rancangan Kitab Undang-Undang Hukum Pidana (RKUHP), RUU Minerba, RUU Pertanahan, RUU Pemasyarakatan dan RUU Ketenagakerjaan.

Pada konteks inilah, pers dengan berbagai platform-nya menjalankan fungsi sebagai jembatan komunikasi antara parlemen dan masyarakat termasuk mahasiswa menuju pemecahan masalah dan menciptakan kondisi ideal. Melalui media, rakyat dari berbagai stakeholders bisa memberikan masukan dan pandanganpandangan kepada parlemen sebagai bahan evaluasi. Sebaliknya, melalui pers, para wakil rakyat pun bisa memberikan penjelasan secara riil dengan daya jangkau luas.

Pers juga menjadi alat bagi rakyat untuk mengontrol jalannya penegakan hukum di negeri ini. Pengawasan yang longgar akan menghasilkan sistem penegakan hukum yang juga tidak sehat. Kondisi ini bisa menjadi awal hancurnya sistem suatu negara. 
Sebab, jika hukum sudah tidak bisa dipercaya, maka negara sesungguhnya sudah tidak ada. Karena itulah penegakan hukum adalah hal yang harus selalu dijaga dan mendapat kontrol ketat secara konsisten dari semua pihak. Termasuk pers.

Namun, untuk melakukan semua fungsi-fungsi itu, mutlak dibutuhkan sistem pers yang sehat dan independen. Salah penandanya adalah para insan pers yang menjunjung tinggi idealisme, kode etik, dan tanggung jawab moral. Pers haruslah bebas dari semua intervensi, baik dari pemerintah, politik, termasuk dari perusahaan pers itu sendiri.

Tetapi berita buruknya, Indonesia termasuk negara yang masih punya nilai merah terhadap kebebasan pers. Pada 2019, Indeks Kebebasan Pers (IKP) Indonesia hanya menduduki peringkat 124 dari 180 negara versi Reporters Without Borders. Bahkan peringkat IKP Indonesia lebih rendah dibanding Timor Leste yang menempati peringkat 93. Peringkat ini disusun atas penilaian terhadap angka abuse score (kekerasan terhadap jurnalis) dan underlying situation score (situasi dan kondisi yang harus dihadapi para jurnalis).

Dua negara yang menduduki peringkat teratas yakni Norwegia dan Finlandia. Dua negara ini dinilai memiliki, melindungi dan mendukung kebebasan pers terbaik dunia. Norwegia menduduki peringkat pertama karena di negara itu, media dan jurnalis dilindungi dari segala tekanan politik dan bebas dari penyensoran.

Norwegia juga memiliki undang-undang untuk mencegah monopoli media, agar media tidak dikuasai oleh satu kepentingan atau pihak tertentu. Negara itu pernah memiliki Undang-Undang Kepemilikan Media yang melarang grup perusahaan untuk memiliki lebih dari 40 persen saham di stasiun TV, stasiun radio, atau surat kabar apapun. 
Namun, aturan ini dicabut pada 2016, dan kini diganti dengan Undang-Undang Transparansi Kepemilikan Media. Yang juga mengatur agar media tidak dijadikan alat kepentingan pihak-pihak tertentu. Dengan aturan-aturan ini, negara itu menjaga independensi pers mereka.

Finlandia juga sangat melindungi kebebasan pers dengan perangkat undang-undang yang tegas dan jelas. Pada Oktober 2018, dua aktivis pro-Putin divonis hukuman berat oleh pengadilan lantaran mencemarkan nama baik dan menguntit seorang jurnalis wanita untuk membungkamnya.

Rakyat Finlandia pun sangat membanggakan kebebasan pers di negaranya. Bahkan hal ini dipamerkan rakyat Finlandia saat Presiden Amerika Serikat Donald Trump berkunjung di Helsinki pada 2018. Semua papan iklan antara bandara hingga pusat kota dipenuhi papan iklan dengan bahasa Inggris dan Rusia yang berbunyi "Pak Presiden, selamat datang di negeri kebebasan pers". Namun, sebenarnya justru Swedia-lah yang menjadi negara yang pertama kali mengesahkan Undang-Undang Kebebasan Pers pada 1775. Sampai sekarang negara itu menjadi yang terbaik dunia dalam hal independensi media.

Sedangkan China dinilai sebagai negara yang memiliki kebebasan pers terburuk di dunia. Tiongkok juga dianggap sebagai negara yang paling menindas para jurnalisnya. Menurut laporan Komite Perlindungan Jurnalis seperti dilansir Independent (12/12/2019), selama 2019, ada 250 wartawan yang dipenjarakan terkait dengan kegiatan jurnalistiknya di seluruh dunia. Dan China memenjarakan 48 orang di antaranya.

\section{Idealisme Jurnalis di Tengah Kapitalisasi Media}

Mewujudkan kebebasan pers tentu bukan perkara enteng. Banyak negara menginginkan itu, namun hanya segelintir yang kemudian 
bisa mewujudkannya. Pada akhirnya, asas kepentinganlah yang berbicara. Ada banyak hal yang harus dibenahi dan dijaga secara konsisten demi mewujudkan cita-cita itu. Kebebasan pers hanya bisa diraih dengan pemerintah yang kuat dan memiliki goodwill yang konsisten, perangkat aturan dan undang-undang yang mendukung, juga pebisnis media yang berkomitmen, kreatif, dan inovatif. Dan salah satu yang terpenting adalah para pekerja pers yang idealis dan bertanggung jawab.

Namun, menjadi seorang jurnalis yang idealis sungguh tidak mudah. Banyak hal yang dipertaruhkan dalam menjalani profesi ini. Sering kali dalam kenyataannya, demi menyajikan sebuah berita yang membawa kebenaran, seorang jurnalis harus mengorbankan waktu, tenaga, bahkan nyawanya sendiri.

Perspektif pertentangan itu, barangkali sejalan dengan apa yang ungkapkan Nielsen, bahwa: "Journalism studies is an ambitious field. It is ambitious in the best possible sense in that we try at the best of our ability to make sense of a complex, ever-changing, and self-reflexive object of analysis. But it is also ambitious in a slightly more problematic manner, in that we tend to have very high ambitions on other people's behalf, and tend to criticize people for not living up to these ambitions (our ambitions, not their ambitions)" (Nielsen, 2017).

Kebenaran yang disampaikannya tentunya tidak bisa memuaskan semua pihak. Tekanan, ancaman, sampai aksi kekerasan kerap dialami para jurnalis di lapangan. Termasuk kekerasan yang justru dilakukan aparat yang seharusnya melindungi mereka dalam melakukan kegiatan jurnalistiknya.

Mengapa demikian, karena menurut pandangan David Cheruiyot, dalam disertasi doktoralnya di Karlstad University Studies Swedia, pasti ada perbedaan pandangan yang tajam antara para aktor jurnalistik dan non jurnalistik. Cheruiyot mengatakan: "Bad 
journalism is often the subject of most criticism of journalism and news organisations, and here I argue they are constituent of discourses about journalism media criticism. Good and bad journalism are part of a larger whole. The assessment of what is considered bad or poor journalism is based on what a variety of actors individually perceive or imagine as good journalism (Örnebring and Jönsson 2004). It is therefore important to underline here that their relationship is not dichotomous, but rather complex owing to different interpretations of the meaning of the two by both journalistic and non-journalistic actors" (Cheruiyot, 2019).

Tapi negeri ini telah terbukti memiliki jurnalis-jurnalis hebat dan memiliki idealisme mumpuni dari masa ke masa. Pada masa perjuangan kemerdekaan, para jurnalis menggunakan "pena"nya sebagai senjata untuk menyuarakan aspirasi rakyat untuk bebas dari penjajahan.

Beberapa nama besar, seperti Bung Hatta, Cipto Mangunkusumo, Tan Malaka, Buya Hamka, Haji Agus Salim, dan Ki Hajar Dewantara adalah para pejuang kemerdekaan yang berprofesi sebagai jurnalis. Dengan militansi tinggi, mereka melontarkan narasi-narasi kritis yang diterbitkan di berbagai media dalam dan luar negeri. Meski dipenjara adalah salah satu buah dari keteguhan mereka dalam mempertahankan idealisme.

Namun, idealisme jurnalis sesungguhnya adalah sebuah hal yang kompleks. Terutama di era modern seperti saat ini, di mana jurnalis sebagai seorang profesional, sekaligus juga bagian dari sebuah indutri media atau bahkan konglomerasi yang tentunya bersifat profit oriented sebagai bagian dari kapitalisasi dan komersialisasi media.

Oleh karena itu, seharusnya media tidak hanya sebagai media informasi, pendidikan dan hiburan yang bersifat profit oriented, 
tetapi juga menjalankan kontrol sosial, dalam konteks menegakkan keadilan, kebenaran, nilai-nilai dasar demokrasi, supremasi hukum dan hak asasi manusia. Media secara aktif melakukan pengawasan berkaitan dengan kepentingan publik. Jaminan seperti ini cukup ideal karena tugas media yang terpenting adalah membela kebenaran dan keadilan. Itulah konteks idealisme media yang sebenar-benarnya. Hal itu bisa dipahami karena diyakini, idealisme adalah sikap hidup yang harus menjadi mindset bagi setiap insan jurnalis, berpijak pada tataran moralitas. Akan tetapi kalangan media sampai kini merasakan kebebasan media (pers) masih terhalang, berbagai tindak kekerasan dan upaya kriminalisasi yang datang dari berbagai pihak, bahkan masih terjadi pembunuhan dan penyiksaan terhadap jurnalis (Alfani, 2017).

Ada banyak hal yang dapat mengancam idealisme itu. Ancaman itu bisa datang dari internal maupun eksternal. Seperti diketahui, media di Indonesia banyak dikuasai oleh konglomerasi tertentu, bahkan banyak pula yang dimiliki secara personal. Hal itu tentunya akan sangat menentukan produk dari media itu sendiri, dan menggerogoti idealisme jurnalis dari dalam.

Lebih celaka lagi, jika para "raja" media itu terkoneksi pula pada kepentingan politik. Sistem seperti ini sering diibaratkan sebagai "kuburan" bagi idealisme jurnalis. Karena, kalau sudah begitu, para jurnalis yang ada di dalamnya sudah akan disetir oleh keinginan sang pemilik media. Menyampaikan kebenaran sudah akan menjadi prioritas nomor ke-sekian.

Jurnalis sudah dirasakan bukan lagi sebagai sebuah profesi, namun tak lebih dari sebuah pekerjaan untuk mencari uang. Hal ini kemudian akan berdampak lebih jauh pada pelaksanaan tugas jurnalistik di lapangan. Para jurnalis tidak akan bisa profesional dalam melaksanakan pekerjaannya, karena telah memiliki orientasi yang berbeda. 
Apalagi di era digitalisasi media seperti sekarang. Membuat sebuah media online begitu mudahnya. Ini melahirkan fenomena baru. Tibatiba banyak sekali muncul jurnalis baru yang melakukan tugas jurnalistik hanya berbekal sebuah kartu pers. Sayangnya, banyak dari para jurnalis itu yang tidak berbekal ilmu maupun pengalaman jurnalisme yang memadai.

Dewan Pers dalam rilisnya mengungkapkan, saat ini ada sekitar 2.000 media online. Tetapi yang sesuai dengan kaidah jurnalistik dan mempunyai kelayakan sebagai perusahaan hanya sekitar 211 media saja. Jika satu media online memiliki puluhan wartawan, bisa dibayangkan betapa banyaknya bermunculan jurnalis-jurnalis baru hanya dengan berbekal sehelai press card.

Suburnya media baru ini tentunya membuka persoalan baru. Penerapan etika jurnalistik dan independensi media dalam pemberitaan menjadi perhatian serius saat ini. Sistem digitalisasi media yang menuntut kecepatan membuat para jurnalis pun mengubah pola kerja mereka. Kalau dulu, sebuah berita hasil investigasi (investigative news) adalah karya jurnalistik bernilai tinggi, sekarang hanya beberapa media saja yang masih menganut nilai-nilai itu.

Mayoritas jurnalis saat ini lebih mengedepankan kecepatan menyajikan berita ketimbang berusaha menghasilkan karya berupa depth news. Ini tampaknya memang tak terelakkan, karena itulah yang menjadi tuntutan sistem media online yang maunya serba cepat, instan, dan up to date.

Selain itu, komersialisasi media yang mementingkan profit juga membuat jurnalis yang tugas utamanya adalah menghasilkan karya jurnalistik, juga dibebani tugas lain. Ikut mencari iklan bagi perusahaan media tempatnya bekerja. Karena memang mayoritas 
media di tanah air menjadikan iklan sebagai sumber utama pemasukan finansial.

Idealnya, seorang jurnalis seharusnya steril dari aktivitas semacam ini. Karena sangat rentan terjadi conflict of interest dalam tugasnya. Seorang jurnalis haruslah independen demi profesinya. Bagaimana mungkin seorang jurnalis bisa profesional jika media tempatnya bekerja menganut prinsip pemasang iklan adalah raja.

Apalagi jika pemasukan iklan bersumber dari kas pemerintah, baik pemerintah pusat maupun pemerintah daerah (APBN/APBD). Maka dipastikan, para jurnalis tidak akan leluasa lagi dalam menyampaikan kritik maupun kontrol terhadap kebijakan-kebijakan pemerintah.

Ini akan menghasilkan efek domino yang sangat panjang, dan rakyat adalah pihak yang paling merugi. Media yang independensinya "tersumbat" iklan akan membuat rakyat tidak memiliki kesempatan untuk menerima informasi yang memadai dan benar. Otomatis rakyat pun terhambat dalam melakukan kontrol maupun menyuarakan aspirasi. Hal ini akan menghasilkan efek yang fundamental, kedaulatan bukan lagi di tangan rakyat.

\section{Pebisnis Media Harus Inovatif dan Berkomitmen}

Untuk mewujudkan pers yang bermartabat, mutlak dibutuhkan pebisnis media yang berkomitmen untuk itu. Pebisnis media senantiasa dituntut inovatif dan kreatif. Karena seperti halnya produk industri lainnya, media juga harus menyesuaikan diri dengan perkembangan zaman.

Mengapa harus inovatif dan kreatif? Sebab inovasi mesti dipahami sebagai "as the introduction of something new and useful in product, processes, or service" (Hernandez, 2010). Inovasi adalah menghasilkan sesuatu yang baru dan bernilai, baik dalam produk, 
proses, atau jasa. Perusahaan yang berhasil menciptakan keunggulan bersaing (competitive advantage) adalah perusahaan yang mampu untuk menciptakan sebuah inovasi dan kreativitas melalui proses inovasi yang efektif dan terencana (Rofaida et al., 2020).

Seperti era digitalisasi seperti sekarang ini, di mana media dituntut untuk mampu menyesuaikan diri dengan keinginan pasar jika ingin bertahan. Maka yang banyak terjadi yaitu pergantian platform media dari cetak menjadi media online, atau paling tidak melakukan konvergensi. Media yang terlambat menyesuaikan diri akan sulit bertahan dan berguguran seiring waktu.

Kenyamanan selama ratusan tahun, sebagai contoh kilas balik, media cetak menjadi media utama yang mendominasi bagi penyebaran informasi. Pers cetak juga menjadi media mainstream di dunia bisnis informasi. Namun, seiring perkembangan teknologi, dominasi industri media cetak kini terancam tergeser. Munculnya internet yang melahirkan pers digital dan multimedia mengubah total peta industri media massa. Meski kalangan pengelola industri media cetak optimistis tentang masa depan bisnis mereka, diakui atau tidak, pengelola pers cetak di Indonesia sebenarnya sedang "galau" (Sholahuddin, 2013).

Pada tahun 2011, sebagai catatan, terjadi sejumlah merger dan akuisisi antar kelompok media di Indonesia. Indosiar Visual Mandiri (Indosiar) dibeli oleh Elang Mahkota Teknologi, perusahaan induk dari Surya Citra Televisi (SCTV). CT Group, perusahaan induk dari Trans TV dan Trans 7, membeli detik.com-salah satu perusahaan media online terbesar di Indonesia. Selain itu, beberapa kelompok media kecil seperti beritasatu.com dibeli oleh Lippo Group. Tentunya, praktik-praktik ini tidak berakhir di sini. Sejumlah akuisisi dan merger akan terus terjadi di masa mendatang, mengingat pertumbuhan industri media di Indonesia (Nugroho et al., 2013). 
Hal itu Karena itulah, pebisnis media harus selalu berinovasi dan kreatif dalam mengemas produk-produk medianya maupun content-nya. Juga dalam mempertahankan independensinya, pebisnis media harus memiliki visi dan kreatif melakukan diversifikasi usaha. Ini dilakukan supaya perusahaan media memiliki kondisi finansial yang kuat dan tahan banting terhadap kondisi ekonomi yang sangat menantang. Terutama di masa pagebluk seperti sekarang ini.

Hal ini bisa dilihat dilakukan oleh dua grup media terbesar tanah air, Kompas Gramedia Grup dan Jawa Pos Grup. Dua grup media ini terbukti masih tetap kokoh dan eksis hingga sekarang. Kompas Gramedia Grup misalnya, meski basisnya adalah sebuah perusahaan media, namun pada kenyataannya grup yang digawangi Jakob Oetama ini memiliki jejaring unit bisnis yang beragam. Mulai dari penerbitan buku, hotel, manufaktur, lembaga pendidikan, properti, sampai produk-produk digital. Tentunya, semua unit bisnis itu dikelola dengan serius dan profesional.

KG Grup memiliki 7 penerbit buku dan lebih dari 120 jaringan toko buku Gramedia yang tersebar di seluruh Indonesia. Grup ini juga memiliki 110 jaringan hotel di seluruh Indonesia dan Singapura melalui grup Hotel Shantika, Hotel Amaris dan lainnya. Juga mengelola 6 lembaga pendidikan dan satu universitas yakni Universitas Multimedia Nusantara (UMN).

Bahkan belakangan, KG Grup juga ikut meramaikan bisnis pada industry meeting, incentive, convention dan exhibition (MICE), dengan membangun venue-venue yang ikonik dan berskala internasional. Salah satu yang fenomenal adalah Indonesia Convention Exhibition (ICE) yang terletak di BSD, Tangerang Selatan. Convention building yang dibangun KG Grup dan Sinarmasland ini adalah salah satu yang terbesar dan termodern saat ini di Indonesia. 
Harus diakui, Jakob Oetama, yang pernah menjadi guru dan mengawali karir jurnalistiknya saat menjadi redaktur di majalah mingguan Penabur pada 1956, telah sukses menjalankan bisnis media yang merupakan bisnis idealisme yang disandingkan dengan bisnis lainnya yang membuat KG Grup begitu kuat dan kokoh secara finansial. Hal ini jelas membuat Kompas dengan beragam platformnya menjadi sebuah media yang independen, bukan media yang hanya menggantungkan nyawanya pada iklan dan advertorial.

Sementara Jawa Pos Group yang dibangun oleh begawan media Dahlan Iskan, grup media terbesar di tanah air juga memiliki jaringan bisnis beragam selain media. Dari bisnis percetakan dan publishing, hotel, listrik dan energi, telekomunikasi, properti, hingga industri pulp and paper. Selain memiliki 151 media di seluruh Indonesia dengan berbagai platform-nya, Jawa Pos Group juga memiliki 26 percetakan, perusahaan energi di Kalimantan Timur dan Riau, juga pabrik kertas.

Inovasi dan kreatif dalam menjalankan bisnis media adalah sebuah keniscayaan dalam mewujudkan sebuah media yang independen dan berkualitas. Karena inilah syarat utama para insan pers untuk menjalankan profesionalis dan idealismenya secara maksimal. Dengan kondisi perusahaan yang mendukung, maka akan tercipta atmosfer yang sehat bagi jurnalis dalam aktivitas jurnalismenya. Menghasilkan produk jurnalistik yang bermanfaat, informatif, mencerahkan dan mencerdaskan masyarakat pembaca. Juga melaksanakan fungsi-fungsi lainnya.

Hal ini sejalan dengan apa yang disebutkan Mark Deuze dalam risetnya yang bertajuk "Media Industries: Work and Life”, bahwa :

"The media industries, in the broadest sense, can be seen as the key drivers and accelerators of a global culturalization of economies. Media are our window to the world, yet also function as its mirror; media reflect and direct at the same 
time. Theorizing the way the media industries operate is understanding the elements of the human condition in the information age - living in a world that can be considered a mediapolis: a mediated public space where media underpin and overarch the experiences of everyday life (Silverstone, 2007). As such, the convergence of production and consumption of media across companies, channels, genres and technologies is an expression of the convergence of all aspects of everyday life: work and play, the local and the global, self and social identity" (Deuze, 2009).

Oleh karena itu, pemerintah maupun legislator harus pula mendukung dan melindungi para pekerja pers melalui perangkat undang-undang dan aturan yang jelas dan tegas. Baik perlindungan terhadap kebebasan berkarya, juga perlindungan terhadap berbagai ancaman dan kekerasan fisik yang kerap dialami para pekerja pers dalam tugas-tugasnya. Termasuk regulasi yang transparan terkait dengan inovasi dalam bisnis industri media, sehingga kehadiran industri media yang sehat dan kapabel benar-benar dapat menjadi pendorong dan akselerator utama dari tumbuh-kembangnya budaya ekonomi yang dapat dinikmati oleh semua pihak.

\section{Penutup}

Media memainkan peran penting dalam kehidupan publik saat ini. Bahkan secara etimologis, kata 'media' memiliki makna locus publicus-sebuah ranah publik. Akan tetapi, seperti yang mungkin juga terjadi di negara-negara lain, media di Indonesia tampak semakin digerakkan oleh motif keuntungan. Meskipun demikian, pemahaman lebih lanjut melihat bahwa media tetaplah sebuah ranah yang diperebutkan oleh berbagai kelompok kepentingan, mulai dari politik dan bisnis hingga blok-blok religiusfundamentalis, yang bersaing untuk meraih kendali dan pengaruh, meskipun terlihat jelas satu pihak memiliki kekuasaan lebih dibanding lainnya. Media terlihat dikendalikan oleh akumulasi 
modal, sehingga industri dapat mengelak dari peraturan-peraturan yang ada, dan pada gilirannya menyebabkan diperbolehkannya penguatan bisnis media melalui akuisisi kanal maupun perusahaan media lain, dengan jumlah yang tidak terbatas (Nugroho et al., 2013).

Walaupun demikian, pers yang idealis (diharapkan) tak akan pernah mati. Tapi, banyak hal yang harus dijaga dan dipenuhi untuk memberikan ruang yang sehat agar idealisme para jurnalis kita tetap tumbuh dan terjaga. Negara kita membutuhkan perspektif yang jernih dari para insan pers. Dan, tentu saja, pers juga adalah instrumen yang paling baik dalam peningkatan kualitas manusia sebagai makhluk rasional, moral dan sosial. Termasuk dalam menjamin berjalannya prinsip-prinsip transparansi dalam penyelenggaran negara.

Mengutip Dalai Lama: "The lack of transparency results in distrust and a deep sense of insecurity". Tidak adanya transparansi akan menghasilkan ketidakpercayaan dan rasa tidak aman yang mendalam. Tentu kita semua tidak ingin itu terjadi di negara yang kita cintai ini.

Demikian hal dengan industri media. Inovasi dan kreativitas di era teknologi informasi dan komunikasi yang melahirkan era digitalisasi, mesti disikapi dengan sangat serius untuk menjaga eksistensinya sebagai salah satu pendorong dan akselerator pertumbuhan ekonomi yang berkelindan dengan sektor-sektor lainya.

Mengapa mesti diatur dengan regulasi yang jelas dan tegas? Karena, industri media di Indonesia sudah mengarah ke industri yang oligopolistik dan hegemonik. Bersamaan dengan pertumbuhan industri media yang sangat cepat, konsentrasi kepemilikan media tidak bisa dihindari, dan menjadi nyata terlihat 
dalam penelitian ini. Konglomerasi menjadi ciri perkembangan industri media di Indonesia, membuat khalayak menjadi hanya sekadar konsumen, bukan warga negara yang memiliki sejumlah hak terhadap media. Ada implikasi ganda dari pola perkembangan industri media saat ini: pertama, pola perkembangan industri media dewasa ini telah membahayakan peran publik di dalam bermedia; kedua, pola ini membuat peran warga negara seolah tidak berarti dalam proses pembentukan cara kerja media (Nugroho et al., 2013).

Pada akhirnya, catatan penting dalam tulisan ini, bahwa retasan jalan dalam merumuskan lanskap idealisme jurnalis dan inovasi bisnis industri media, barangkali haruslah tetap menjunjung tinggi tujuan luhur kehadiran media dengan aktivitas jurnalistiknya bagi kepentingan publik. Media tetaplah properti publik, locus publicus (ranah publik) harus adil dalam menciptakan sekaligus memberikan ruang publik (public sphere) bagi semua kalangan tanpa terkecuali.

Memang harus diakui, bahwa idealisme jurnalis dan inovasi bisnis industri media, adalah dua kutub yang sering kali bertolak belakang, karena dipengaruhi oleh berbagai konteks dan pokok soal kepentingan (interest). Akan tetapi, sesungguhnya, kedua kutub ini saling membutuhkan. Sebab, tidak akan pernah ada jurnalis dan idealismenya, ketika organisasi atau perusahaan medianya tidak lahir dan berdiri. Pun sebaliknya, tidak akan pernah tumbuh dan besar suatu perusahaan media, ketika para jurnalisnya tidak pernah menjalankan aktivitas jurnalistiknya.

Mungkin analisa itu terlalu klise, bahkan naif! Tapi itulah kenyataan dan faktanya. Walaupun sering kali saling bertolak belakang, tetapi kedua kutub itu saling membutuhkan satu sama lain. Hilang salah satunya, maka keduanya akan mati bersama. Hidup kedua-duanya, maka coraknya akan terus berwarna bersama dinamisnya dinamika 
perkembangan zaman. Koneksi keduanya, seperti kondisi cuaca di musim pancaroba; naik turun dan berubah-ubah. $\left(^{*}\right)$

\section{Referensi}

Alfani, H. (2017). Tantangan Idealisme Media di Era Kapitalisme Global. Mediakom: Jurnal IImu Komunikasi, 1(1), 80-96.

Cheruiyot, D. (2019). Popular Media Criticism in the Digital Age. Doctoral Thesis Karlstad University Studies Swedish. Universitetstryckeriet, Karlstad 2019.

Darmanto. (2015). Urgensi Perubahan Kebijakan Untuk Penegakkan Independensi Media Di Indonesia. Jurnal Komunikasi, 10(1), 29-39. https://doi.org/10.20885/komunikasi.vol10.iss1.art4

Deuze, M. (2009). Media industries, work and life. European Journal of Communication, 24(4), 467-480. https://doi.org/10.1177/0267323109345523

Kusuma, S. (2016). Posisi Media Cetak di Tengah Perkembangan Media Online di Indonesia Satria Kusuma. InterAct Program Studi Ilmu Komunikasi FIABIKOM Unika Atmajaya Jakarta, 5(1), 56-71.

Nielsen, R. K. (2017). The One Thing Journalism Just Might do for Democracy: Counterfactual idealism, liberal optimism, democratic realism. Journalism Studies, 18(10), 1251-1262. https://doi.org/10.1080/1461670X.2017.1338152

Samatan, N. (2009). STRATEGI PENGEMBANGAN MEDIA : ANTARA BISNIS DAN IDEOLOGI. Jurnal Ekonomi Dan Bisnis, 14(3), 190-199

Razali, G. (2019). Strategi Mnc Group Dalam Meningkatkan Efisiensi Dan Kompetisi Di Pasar Bisnis Industri Media Penyiaran 4.0. Jurnal IImu Komunikasi, 6(1), 33-42. https://doi.org/10.33822/jep.v2i1.973

Rofaida, R., Suryana, Asti Nur Aryanti, \& Yoga Perdana. (2020). Strategi Inovasi pada Industri Kreatif Digital: Upaya Memperoleh Keunggulan Bersaing pada Era Revolusi Industri 4.0. Jurnal Manajemen Dan Keuangan, 8(3), 402-414. https://doi.org/10.33059/jmk.v8i3.1909

Sholahuddin. (2013). Strategi Pengembangan Produk di Industri Media Cetak di Indonesia (Bertahan di Tengah Persaingan dengan Media Online). BENEFIT Jurnal Manajemen Dan Bisnis, 17(1), 9-17. http://journals.ums.ac.id/index.php/benefit/article/download/1375/931 


\section{Profil Penulis}

Hendra Alfani, lahir di Baturaja, Ogan Komering Ulu, Sumatera Selatan, pada tanggal 27 Januari 1974. Menempuh pendidikan dasar dan menengah (SD, SMP dan SMA) di Baturaja rentang tahun 1981-1993. Menyelesaikan pendidikan Sarjana di Jurusan Ilmu Komunikasi (Konsentrasi Jurnalistik) di STPMD “APMD” Yogyakarta (1995-1999), Magister Ilmu Komunikasi (Konsentrasi Komunikasi Politik dan Media) di FIKOM UMB Jakarta (2008-2011) dan Program Doktoral IImu Komunikasi (Konsentrasi Media dan Jurnalistik) FIKOM UNPAD Bandung (2015-2018). Pernah menjadi wartawan di Harian Sumatera Ekspres Palembang Jawa Pos Group (2000-2001). Aktif dalam pertemuan ilmiah (peserta dan narasumber). Aktif menulis berbagai topik tentang media, jurnalistik dan komunikasi politik di jurnal ilmiah, buku, book chapter dan media massa (cetak/online). Pekerjaan Dosen Tetap di Prodi Ilmu Komunikasi FISIP Universitas Baturaja Sumatera Selatan, dan Dosen LB di Program Studi Magister Ilmu Komunikasi STISIPOL Candradimuka Palembang. Tahun 2009 mendirikan Lingkar Prakarsa Institute, sebuah lembaga jasa konsultasi riset, diklat dan pemberdayaan masyarakat. Penulis dapat dihubungi di email: hefanila02@gmail.com

Masayu Indriaty Susanto, Lahir di Palembang, 22 Januari 1976. Mengawali karir sebagai reporter desk politik pada Harian Palembang Pos di Palembang (2000-2002), dan menjadi redaktur halaman Metropolis di harian yang sama yang berisikan berbagai isu terkait perkotaan dan politik. Pada 2002 ditugaskan menempuh pendidikan sebagai reporter Harian Jawa Pos di Surabaya. Karirnya kemudian berlanjut sebagai senior editor di Harian Indopos di Jakarta (2003-2008). Tugas selanjutnya yaitu di Harian Riau Pos Pekanbaru (2008-2012). Selama belasan tahun karir jurnalistiknya, penulis telah melakukan berbagai liputan nasional maupun internasional. Meskipun studi mayornya adalah kimia, namun alumni FMIPA Jurusan Kimia Universitas Sriwijaya ini sangat menyukai dan banyak menulis artikel seputar politik, sains, budaya, kuliner, sejarah, filsafat, pendidikan dan psikologi parenting. Saat ini Masayu adalah jurnalis dan kolumnis di beberapa media online. Juga menulis buku. Pada 2021 Masayu menerbitkan buku antologi esai berjudul "My Window; Passion for 
Journalism", yang berisi kumpulan tulisan-tulisannya yang telah diterbitkan di berbagai media online maupun cetak. Masayu Indriaty Susanto bisa dihubungi melalui email: masayuindriatysusanto@gmail.com. 